Colloquium Rauricum Band 13

Politische Partizipation 


\section{Colloquia Raurica}

Die Colloquia Raurica werden alle zwei Jahre vom Collegium Rauricum veranstaltet. Sie finden auf Castelen, dem Landgut der Römer-Stiftung Dr. René Clavel in Augst (Augusta Raurica) bei Basel, statt. Jedes Colloquium behandelt eine aktuelle geisteswissenschaftliche Frage von allgemeinem Interesse aus der Perspektive verschiedener Disziplinen. Einen Schwerpunkt bilden dabei Beiträge aus dem Bereich der Altertumswissenschaft. Um möglichst vielseitig abgestützte Erkenntnisse zu gewinnen, erörtern die eingeladenen Fachvertreter das Tagungsthema im gemeinsamen Gespräch. Die Ergebnisse werden in der Schriftenreihe Colloquia Raurica publiziert.

Das Collegium Rauricum

Jürgen von Ungern-Sternberg

Peter Blome

Joachim Latacz

Hansjörg Reinau

De Gruyter 
Colloquium Rauricum Band 13

\title{
Politische Partizipation
}

\author{
Idee und Wirklichkeit \\ von der Antike bis in die Gegenwart
}

\author{
Herausgegeben von \\ Hansjörg Reinau \\ und \\ Jürgen von Ungern-Sternberg
}

De Gruyter 
ISBN 978-3-11-030333-9

e-ISBN 978-3-11-030343-8

ISSN 1616-1157

\section{Library of Congress Cataloging-in-Publication Data}

A CIP catalog record for this book has been applied for at the Library of Congress.

Bibliografische Information der Deutschen Nationalbibliothek

Die Deutsche Nationalbibliothek verzeichnet diese Publikation in der Deutschen Nationalbibliografie; detaillierte bibliografische Daten sind im Internet über http://dnb.dnb.de abrufbar.

(C) 2013 Walter de Gruyter GmbH, Berlin/Boston

Druck: Hubert \& Co. GmbH \& Co. KG, Göttingen $\infty$ Gedruckt auf säurefreiem Papier

Printed in Germany

www.degruyter.com 